\title{
Prevalence of Thyroid Disorders in Patients in Two Tertiary Care Hospitals at Palakkad: A Prospective Study
}

\author{
Deepthi GovindanKutty ${ }^{1}$, Dhanya.C. S ${ }^{2}$, C. I. Sajeeth ${ }^{3}$ \\ ${ }^{I}$ Department of Pharmacy Practice, Grace College of Pharmacy, Kerala \\ ${ }^{2}$ Department of Pharmacy Practice, Grace College of Pharmacy, Kerala \\ ${ }^{3}$ Head of the Department, Department of Pharmacy Practice, Grace College of Pharmacy, Kerala
}

\begin{abstract}
Introduction: In the present study, the prevalence and pattern of thyroid disorders in patients attending two tertiary care hospitals with different co morbidities were assessed. Aim: The aim was to find the prevalence of different types of thyroid disorders and prevalence of different comorbidities in patients with hypothyroidism. Methods: The study was a prospective observational study by verifying patient's data records, using pre-designed questionnaire and direct patient interview. 120 cases were collected during a 4 months study period from both the tertiary care hospitals. The biochemical parameters were glycemic control (fasting and post prandial blood glucose levels, total cholesterol, blood pressure, thyroid profile (TSH, free $T_{3}$, and free $T_{4}$ ) and other routine laboratory investigations. These parameters were verified and assessed. Results: Prevalence of thyroid disorders were seen more in female population and no. of patients with hypothyroidism was high. Type 2 Diabetes mellitus was the most common comorbidty presenting with hypothyroidism. Among the diabetic population with hypothyroidism, females were more prevalent. Conclusion: This study suggests that in the female population, $T_{2} D M$ and Hypothyroidism are prevalent both individually and jointly.
\end{abstract}

Keywords: Diabetes Mellitus, Hypothyroidism, Thyroid dysfunction, TSH

\section{Introduction}

Thyroid disorders vary according to the geographic location, environmental factors, major radio nuclear events, factors affecting the onset and persistence of iodine-deficiency as well as iodine excess in diet and the population studied [1]. It is a spectrum of disorders of the thyroid gland which manifests either as hyper - or hypothyroidism and is reflected in the circulating levels of thyroid stimulating hormone (TSH). Thyroid hormones, namely Tri-iodothyronine $\left(\mathrm{T}_{3}\right)$ and Thyroxine $\left(\mathrm{T}_{4}\right)$; either or both of which may be elevated or reduced have both direct and indirect effects on blood glucose homeostasis. Elevated levels of free circulating thyroid hormones (hyperthyroidism) produce hyperglycaemia by causing polyphagia, enhancing glucose absorption from the gastro-intestinal tract, accelerating insulin degradation and stimulating glycogenolysis. Reduced levels of the hormones (hypothyroidism) may cause hypoglycaemia[2]. The prevalence of thyroid disorders has been found to increase linearly with age and virtually all thyroid diseases are common in women [1].

The WHO estimate of diabetes prevalence for all age groups world wide was $2.8 \%$ in 2000 and $4.4 \%$ in 2030. The total no. of people with diabetes is projected to rise from 171 million in 2000 to 366 million in 2030 . Factors such as sedentary lifestyle, dietary modifications, ethnicity, hypertension and obesity have led to a dramatic increase in the incidence of diabetes mellitus, especially in the $21^{\text {st }}$ century. Thyroid disorders are also very common in the general population and it is second only to diabetes as the most common condition to affect the endocrine system. As a result it is common for an individual to be affected by both thyroid diseases and diabetes. The first report showing the association between diabetes and thyroid dysfunction were published in 1979. Since then a number of studies have estimated the prevalence of thyroid dysfunction among diabetes patients to be varying from 2.2 to $17 \%$. However, fewer studies have estimated much higher prevalence of thyroid dysfunction in diabetes i.e. $31 \%$ and $46.5 \%$ respectively [1].

Diabetes mellitus (DM), a common endocrine metabolic disorder, is a leading cause of death worldwide. It is characterized by hyperglycemia resulting from a variable interaction of hereditary and environmental factors and is due to the combination insulin resistance (impairment in insulin-mediated glucose disposal) and defective secretion of insulin by pancreatic $\beta$-cells or both. Thyroid hormones are insulin antagonists, both insulin and thyroid hormones are involved in cellular metabolism and excess and deficit of any one can result in functional derangement of the other. Thyroid disease is a pathological state that adversely affects diabetic control and is commonly found in most forms of DM which is associated with advanced age in type 2 diabetes and autoimmune diseases in type 1diabetes. DM appears to influence thyroid function in two sites; firstly at the level of hypothalamic control of TSH release and secondly at the conversion of T4 to T3 in the peripheral tissue. Marked hyperglycemia causes reversible reduction of the activity and hepatic concentration of T4-5-deiodinase, low serum concentration of T3, elevated levels of reverse T3 and low, 
normal, or high level of T4 . Since thyroid hormones regulate metabolism and diabetes an alter metabolism of food stuff, the metabolism of organisms may be further affected of the combination of thyroid disease and diabetes[5].

Thyroid hormones directly control insulin secretion. In hypothyroidism, there is a reduction in glucoseinduced insulin secretion by beta cells, and the response of beta cells to glucose or catecholamine is increased in hyperthyroidism due to increased beta cell mass. Moreover, insulin clearance is increased in thyrotoxicosis[4].

Till date not much data is available about thyroid diseases in diabetes among the population of Palakkad, Kerala. Therefore, the aim of the present study was to evaluate the prevalence of thyroid dysfunction in in two tertiary care hospitals at Palakkad, Kerala and the prevalence of different comorbidities presenting with hypothyroidis[3].

\section{Materials And Method}

The study was designed as a prospective observational study and was conducted among the Inpatients and Outpatients of ENT, MED, OBG departments at two tertiary care hospitals in Palakkad. The study population comprises of all subjects including those with thyroid disease, risk factors and medications.

Ethical committee clearance was obtained from the Institutional Ethical Committee of Grace College of Pharmacy on May $15^{\text {th }} 2013$.

\subsection{Study criteria}

\subsubsection{Inclusion Criteria}

Patients with abnormalities of thyroid function in the age group of 18-80 years.

Patients willing to participate in the study.

\subsubsection{Exclusion Criteria}

Patients unwilling to co-operate.

Patients diagnosed with thyroid cancer.

\subsubsection{Data collection method}

The data collection was done using pre-designed patient data entry form and by direct personal interview. A total of 120 patients were included in the study which was conducted in a 4 month study period at two tertiary hospitals at Palakkad. General health characteristics such as age, sex, smoking status, menopausal status, alcohol consumption, and dietary habits were investigated by a pre-designed questionnaire.

\subsubsection{Collection of Blood samples}

$2.0 \mathrm{ml}$ of venous blood was collected from the subjects attending both the tertiary care hospitals at Palakkad. Blood collected in plain vial was allowed to clot and centrifuged at $3000 \mathrm{rpm}$ for 15 minutes. The separated serum was stored at $-20^{\circ} \mathrm{C}$ for hormone assay.

\subsubsection{Assay of thyroid function panel}

Thyroid function test panel ( $\mathrm{T}_{3}, \mathrm{~T} 4$ and TSH) were assayed by the ELISA method using standard kit.

\section{Results And Discussion}

TABLE 1 presents the sex distribution of patients with thyroid disorders. Among the 120 patients enrolled in the study, 26 patients were male patients $(21.66 \%)$ and 94 patients were female patients $(78.33 \%)$.

TABLE. 1 GENDERWISE PREVALENCE OF THYROID DYSFUNCTIONS

\begin{tabular}{|l|l|c|c|}
\hline SL.NO & SEX & NO.OF PATIENTS & \% OF PATIENTS \\
\hline 1. & MALE & 26 & 21.66 \\
\hline 2. & FEMALE & 94 & 78.33 \\
\hline
\end{tabular}

TABLE 2 shows the prevalence of different types of thyroid disorders among the 120 patients. The most prevalent were patients with hypothyroidism, 84(70\%). Hyperthyroidism patients were $18(15 \%)$. Patients suffering from mixed nodular goiter were 5 (4.16\%). Post thyroidectomy hypothyroidism patients were 9 (7.5\%). Patients with Hashimoto's thyroiditis were 4 (3.33\%). 
TABLE 2: PREVALENCE OF DIFFERENT TYPES OF THYROID DISORDERS

\begin{tabular}{|l|l|c|c|}
\hline SL.NO. & THYROID DISORDER & NO. OF PATIENTS & \% OF PATIENTS \\
\hline 1. & HYPOTHYROIDISM & 84 & 70 \\
\hline 2. & HYPERTHYROIDISM & 18 & 15 \\
\hline 3. & MIXED NODULAR GOITRE & 5 & 4.16 \\
\hline 4. & POST THYROIDECTOMY HYPOTHYROIDISM & 9 & 7.5 \\
\hline 5. & HASHIMOTO'S THYROIDITIS & 4 & 3.33 \\
\hline
\end{tabular}

TABLE 3 shows the assessment of number of patients with different co morbidities presenting with hypothyroidism. Patients with hypothyroidism and hypertension were $20(16.67 \%)$ and patients with hypothyroidism and hyperlipidemia were 19 (15.83\%), patients with hypothyroidism and type 2 Diabetes mellitus were the highest, $43(35.83 \%)$. Patients with hypothyroidism and other diseases were found to be 10 $(8.33 \%)$ and patients with hypothyroidism with no presenting co morbidities were 28 patients (23.33\%).

TABLE 3. PREVALENCE OF DIFFERENT COMORBITIES WITH HYPOTHYROIDISM

\begin{tabular}{|l|l|c|c|}
\hline SL.NO. & DISEASE COMORBIDITIES WITH HYPOTHYROIDISM & NO. OF PATIENTS & \% OF PATIENTS \\
\hline $\mathbf{1 .}$ & HYPOTHYROIDISM WITH HYPERTENSION & 20 & 16.67 \\
\hline $\mathbf{2 .}$ & HYPOTHYROIDISM WITH HYPERLIPIDEMIA & 43 & 15.83 \\
\hline $\mathbf{3 .}$ & HYPOTHYROIDISM WITH DIABETES MELLITUS & 10 & 35.83 \\
\hline $\mathbf{4 .}$ & HYPOTHYROIDISM WITH OTHER DISEASES & 28 & 8.33 \\
\hline $\mathbf{5 .}$ & HYPOTHYROIDISM WITHOUT ANY COMORBIDITIES & & 23.33 \\
\hline
\end{tabular}

TABLE 4 compares the number of male and female patients among the diabetic population suffering from hypothyroidism. We have observed that out of the 43 diabetic patients with hypothyroidism, 35 of them were female patients $(81.39 \%)$. Male patients were 8 patients $(18.6 \%)$ who had suffered from hypothyroidism and type 2 diabetes mellitus.

TABLE 4. GENDERWISE DISTRIBUTION OF DIABETIC PATIENTS WITH HYPOTHYROIDISM

\begin{tabular}{|l|l|c|c|}
\hline SL.NO. & SEX & NO. OF PATIENTS & \% OF PATIENTS \\
\hline 1. & MALE & 8 & 18.6 \\
\hline 2. & FEMALE & 35 & 81.39 \\
\hline
\end{tabular}

\section{GENDERWISE PREVALENCE OF THYROID}

DYSFUNCTIONS

MALES FEMALES

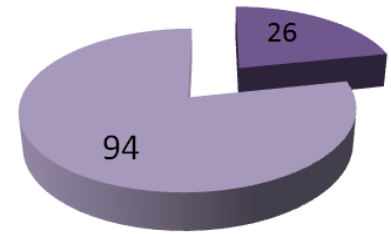

FIG. 1 GENDERWISE PREVALENCE OF THYROID DYSFUNCTIONS

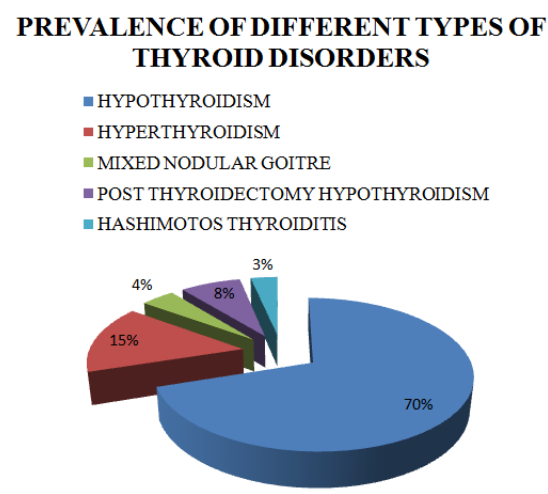

FIG. 2 PREVALENCE OF DIFFERENT TYPES OF THYROID DISORDERS 


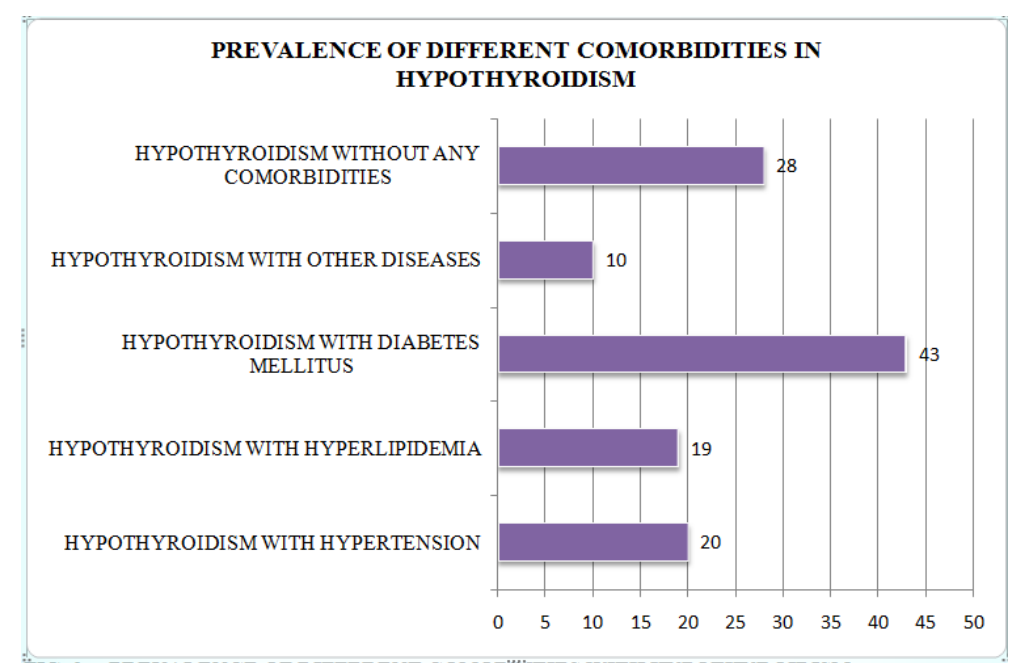

FIG. 3 PREVALENCE OF DIFFERENT COMORBITIES WITH HYPOTHYROIDISM

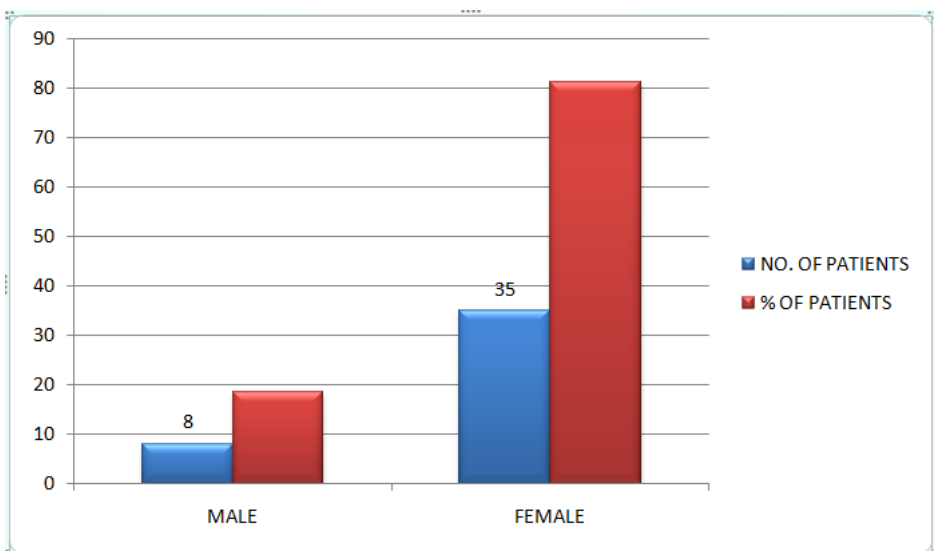

FIG.4 GENDERWISE DISTRIBUTION OF DIABETIC PATIENTS WITH HYPOTHYROIDISM

\section{Conclusion}

Estimates of the prevalence of thyroid dysfunction depend upon methodological factors, classifications of hypothyroidism, and composition of the community examined by age, ethnicity, and gender, making comparisons between studies of limited value. The prevalence and pattern of hypothyroidism depend on ethnic, geographic, and environmental factors including iodine intake status. In this study, hypothyroidism is more prevalent among the different thyroid disorders.

The prevalence of thyroid dysfunction is higher in Type 2 DM than that in the general population, more females are affected than are males. Hyperlipidemia is almost always present in hypothyroid type 2 diabetics. Routine screening and regular monitoring of type 2 Diabetics for thyroid dysfunction is recommended for better quality of life. During the study period, we observed a high prevalence of both disorders together in the female population of Palakkad, Kerala. The female predominance of developing $\mathrm{T}_{2} \mathrm{DM}$ and thyroid dysfunction is high. This finding supports the higher than normal prevalence of these two major metabolic disorders at the same time in the female population. This may also support the observation that thyroid autoimmunity is common in $\mathrm{T}_{2} \mathrm{DM}$ female patients.

\section{Acknowledgement}

We acknowledge the valuable support from Karuna Medical College Hospital and Paalana Institute of Medical Sciences, Palakkad. The authors are grateful to the Associate Professors, General Medicine Dept., the nursing staff and Bio-chemistry Laboratory staff, Karuna Medical College Hospital and Paalana Institute of Medical Sciences, Palakkad Hospital for their co-operation and skillful technical assistance. 


\section{References}

[1] E.M.Der, S.E. Quayson, J.N. Clegg-Lamptey, E.K. Wiredu, R. K. D. Ephraim and R. K. Gyasi, Thyroid disorders in Accra, Ghana: A Retrospective Histopathological Study at the Korle-Bu Teaching Hospital, Journal of Medical and Biomedical Sceinces , 2(1), 2013, $1-7$

[2] Ghazali S. M and Abbiyesuku F. M, Thyroid dysfunction in type 2 diabetics seen at the University College Hospital, Ibadan, Nigeria, Nigerian Journal of Physiological Sciences, 25, 2010, 173 - 179.

[3] Gurjeet Singh, Vikas Gupta, Anu Kumar Sharma and Neeraj Gupta, Evaluation of Thyroid Dysfunction Among Type 2 Diabetic Punjabi Population, Advances in Bioresearch, 2(2), 2011, 3-9.

[4] ChaoxunWang, The Relationship between Type 2 Diabetes Mellitus and Related Thyroid Diseases, Journal of Diabetes Research, 2(4), 2013, 33-38.

[5] Vinu Vij, Pallavi Chitnis and Vijay Kumar Gupta, Evaluation of Thyroid Dysfunction among type II diabetic patients, International Journal of Pharmacy and Biological Sciences, 2(4), 2012, 150-155

[6] Rebecca Abraham, V Srinivasa Murugan, P Pukazhvanthen and S.K.Sen, Thyroid disorders in women of Puducherry, Indian Journal of Clinical Biochemistry, 24(1), 2009, 52-59.

[7] Nimmy N.J, Aneesh.P.M, Narmadha M.P, Udupi R. H and Binu K. M, A Survey on prevalence of thyroid disorder induced by demography and food habits in South Indian Population, Indian Journal of Pharmacy Practice, 5(2), 2012, 49-52.

[8] Samaneh Khanpour, Ammar Hassanzadeh Keshteli, Noushin Khalili, Mahin Hashemipour, and Reihaneh Barekatain, Thyroid disorders in children and adolescents with Type 1 Diabetes mellitus in Isfahan, Iran, Iranian Journal of Pediatrics, 21(4), 2011, 502-508.

[9] Madhukar Aryal, Prabin Gyawali, Nirakar Rajbhandari, Pratibha Aryal and Dipendra Raj Pandeya, A Prevalence of thyroid dysfunction in Kathmandu University Hospital, Nepal, Biomedical Research, 21(4), 2010, 411-415.

[10] Athanasia Papazafiropoulou, Alexios Sotiropoulos, Anthi Kokolaki, Marina Kardara, Petroula Stamataki and Stavros Pappas, Prevalence of thyroid dysfunction among Greek Type 2 Diabetic patients attending and Outpatient clinic, Journal of Clinical and Medical Research, 2(2), 2010, 75-78.

[11] Palaniswamy Pasupathi, Govindaswamy Bakthavalsalam, Ganesan Saravanan and Ramachandram Sundaramoorthi, Screening for thyroid dysfunction in the diabetic/non-diabetic population, Thyroid Science, 3(8), 2008, 1 - 4.

[12] S.Shreshta, B.K.L.Das, N. Baral and L. Chandra, Association of metabolic syndrome and its components with thyroid dysfunction in females., International Journal of Diabetes in developed countries, 27(1). 2007, 24-27.

[13] Raj Kumar Yadav, Namrata Thapa Magar, Bibek Poudel, Naval Kishor Yadav and Binod Yadav, A prevalence of thyroid disorder in western part of Nepal, Journal of Clinical and Diagnostic Research, 7(2), 2013, 193-196.

[14] Naval Kishor Yadav, C.Thanpari, Mukesh Kumar Shrewatsa, Brijesh Sathian and Rabindran Kumar Mittal, Sociodemographic wise risk assessment of thyroid function abnormalities in far western region of Nepal: A hospital based descriptive study, Asian Pacific Journal of Tropical Disease, 3(2), 2013, 150-154.

[15] Sanjay Kalra, Bharti Kalra and Girish Chatley, Prevalence of hypothyroidism in pediatric type 1 diabetes mellitus in Haryana, Northern India, Thyroid research and practice, 9(1), 2012, 12-14. 